authority and a wide range of discussion around the main theme. The material is well presented and adequately illustrated, and the various authors have interpolated sufficient pertinent speculation both about future lines of investigation and the interpretation of present results to sustain interest through some of the more involved passages. It is guaranteed a wide readership and, although an expensive publication, is a worthy accession to any library.

R. K. Robinson

\section{RUSSIAN FORESTS}

The Forests of the U.S.S.R.

By V. P. Tseplyaev. Translated from the Russian by A. Gourevitch. Pp. v+521. (Jerusalem: Israel Program for Scientific Translations; London: Oldbourne Press, 1965.) $138 s$.

A GENERAL introductory chapter covers the classification and general features of the forests of the Soviet Union, and is followed by a short survey of forest distribution, by area, in the several republics of the Soviet Union. An account of forest zonation is given in the third chapter and this is followed by the principal parts of the booktwo chapters descriptive of the different types of forests in the Soviet Union. One chapter covers coniferous and the other broad-leafed forests. Forests are dealt with according to the predominant type of tree-pine, fir, larch, oak, for example-so that mixed forests may be found under more than one heading. The more important or extensive types of forest are further subdivided geographically. For each of them there is a short history and account of forest husbandry and exploitation, a briof descriptive account of forest physiognomy, flora and fauna, an indication of quality of the stands, a survey of regeneration, and a statistical survey of forest area, age characteristics, reserves, usage and increment. Much of the information throughout the book is presented in tabular form. There are also short chapters surveying forest utilization in the Soviet Union and the forest resources of the world (based on the FAO survey of 1953).

The comparative vastness of the forest resources of the Soviet Union is clearly apparent from this book, but it is also clear that this vastness has not blinded Russian foresters to the need to conserve, maintain and properly exploit their forests. It is also evident that there are large areas of the Soviet Union, especially in the drier parts of the Middle Asian republics, where forest resources are negligible and conditions for silviculture difficult. Other areas in the south, such as Dagestan, have clearly suffered and still suffer from the bad effects of over-exploitation, over-grazing and neglect. Russian foresters are also fully aware of the amenity value of forests, particularly in the vicinity of large centres of population. An account of the forests of the Moscow "green belt" is of interest to all who are concerned with the wellbeing of city surroundings.

The English translation reads well and is remarkably free from errors of usage and spelling. It should, however, be noted that "cedar" is used to cover certain Pinus species, not Cedrus, while "aspen" includes more than the one species Populus tremula. A few explanatory notes have been added where necessary, but they do not intrude on the original text. In dealing with official Russian names of organizations and institutes, a happy balance has been struck between translation and transliteration.

Throughout the book there are useful references to forest husbandry and recommended practice in the various forest types and regions of the Soviet Union, but the book is in no way a forestry handbook but rather a source-book or compendium of the forest resources of the Soviet Union in the period 1957-59. For a book of this kind, it is remarkably readable - a reflexion of the love of forests of the original author as well as of the skill of the translator. C. JefFrey

\section{NOBEL SYMPOSIUM}

\section{Muscular Afferents and Motor Control}

Edited by Ragnar Granit. (Proceedings of the First Nobel Symposium held in June 1965 at Södergarn, Lidingö, County of Stockholm.) Pp. 466. (New York and London: John Wiley and Sons; Stockholm: Almqvist and Wiksell, 1966.) 150s.

THIS record of the first Nobel symposium contains some 450 pages of scientific papers in 39 separate contributions by 61 authors, most of whom were present at the discus. sions. We are told in the preface that "it was decided not to publish the lively discussions that took place, unless the discussants themselves wanted it and were prepared to deliver signed contributions". Regrettably for those who set a high value on this form of thinking aloud, very few of the participants delivered their signed contributions, so that only six pages of the volume are given over to discussion. It would, of course, have greatly lengthened the book had discussion been included and perhaps the task of collation and publication would have been exceedingly difficult. The reader is bound to be curious, however, as to what was actually said in discussion of many of the arguable and open statements in these papers.

The inaugural paper by Lord Adrian stresses the importance of this Nobel Foundation experiment in a new technique. He says "Scientists, therefore, are learning how to profit by the classical method, the symposium of experts, few enough to sit round a room, with a definite subject on their agenda and a chairman ... like Socrates ... to keep them to the point", and later ". . . we hope to go home with clearer ideas about the nervous apparatus which regulates muscular contraction so that movements are smooth and posture is adjusted to suit them. The subject is ripe for discussion". But the general reader of this important volume has been prevented from sharing those clearer ideas about nervous action contributed to the discussion. By the publication of the Proceedings of this first Nobel symposium in the present form he is scarcely better off than if the papers had been published without the contributors ever having visited Stockholm.

It is scarcely possible to summarize or even to review the contents of the volume, dealing as it does with nearly forty topics within the very wide scope of its title, from the structural aspects of mammalian muscle spindles through the analysis of their responses to the peripheral and central mechanisms of control of motor systems in man and the cat. It is obvious, however, that this collection of papers will form a valuable source of reference on the sensory apparatus of muscle and the control of motor function. It will particularly serve the needs of those bio-cyberneticians interested in developing theoretical concepts about central nervous activity and the theory of action of tho neuro-musculature. In it they will find many suggestions and ideas about possible mechanisms for regulation and control in the central and peripheral nervous and motor systems.

One of the difficulties in writing meaningful accounts of experimental work in neuro-physiology is the vast amount of detail that must be put on record in any statement of results, if the statement is to have any value at all either in its own right or in comparison with other work. The problem is made more difficult by differences over nomenclature. It is especially to be regretted that the final day's discussion on this topic has not been reported.

The difficulty of complexity can be overcome in two ways-by well formulated theory and more research 